\title{
The True Meaning of IFSO
}

\author{
Scott A. Shikora
}

Published online: 23 September 2012

(C) Springer Science+Business Media New York 2012

The abbreviation, IFSO, stands for the International Federation for the Surgery of Obesity (and Metabolic Disorders) and is the name of an international community of clinicians committed to the treatment of extreme obesity and related metabolic disorders. Although the name seems appropriately descriptive, I have always suspected that IFSO meant very much more. This year's amazing World Congress in New Delhi, India confirmed my belief.

Over the years, I have attended many IFSO meetings, and in doing so, visited many interesting places around the world. Each venue offered up opportunities to learn about the many interesting and diverse cultures of the members of our organization. While I always looked forward to experiencing the rich scenery and the daily life of the local people, mostly, I couldn't wait to see my many friends and colleagues from around the world. Only in an organization such as IFSO can a boy born in New York City from humble roots be blessed with knowing so many people around the world, many of whom are world leaders in their fields.

This year's meeting, held in New Delhi, India, was the most unique, and in a way, the most special. In addition to the scientifically strong program and rich social program, the Congress participants were blessed to have His Holiness, the Dalai Lama attend. This was a truly amazing and unforgettable experience. No matter what your religious beliefs are, the Dalai Lama's message of peace and love touches all hearts. His Holiness came on the morning of the second day. He spoke without notes and from his heart for almost an hour. He spoke about the importance of tolerance and that all people are brothers and sisters to one another. He then greeted a long procession of attendees who had the opportunity to shake his hand and to speak with him individually. I was fortunate enough to be one of them.

It has long been my observation that the tolerance and respect His Holiness spoke about was already a trait of IFSO. I have for many years noticed that IFSO members are comprised of peoples from all over the world. All religions, races and ethnic groups are represented. In IFSO, our members are respectful and even compassionate to one another. Members from regions of geopolitical conflicts and long-time hostilities shake hands, break bread together, and work together for the common goals of improving the lives of patients suffering from metabolic disease. True friendships exist for individuals who otherwise might have never met. Politics and prejudices do not enter into the mission or actions of the federation.

The Dalai Lama reminded us that we are all the same and have shared interests and goals for life. I think IFSO already stood for that. Maybe our world leaders could learn a thing or two from IFSO.

Scott A. Shikora, MD, FACS, FASMBS

Editor-in-Chief

Obesity Surgery

S. A. Shikora $(\square)$

Brigham and Women's Hospital,

75 Francis Street,

Boston, MA 02115, USA

e-mail: tracy.marton@springer.com 